\title{
Field evaluation of a novel synthetic odour blend and of the synergistic role of carbon dioxide for sampling host-seeking Aedes albopictus adults in Rome, Italy
}

Marco Pombi ${ }^{1 *}$, Frans Jacobs ${ }^{2}$, Niels O Verhulst ${ }^{2}$, Beniamino Caputo ${ }^{1}$, Alessandra della Torre ${ }^{1}$ and Willem Takken ${ }^{2}$

\begin{abstract}
Background: Despite the expanding worldwide distribution of Aedes albopictus and its increasing relevance as arboviral vector, current methods to collect adult specimens are not optimal. Improved approaches are thus needed to monitor their density and pathogen infections, and to establish baseline data for control interventions. A widely used device is the BG-Sentinel (BG-trap) which mostly targets host-seeking females attracted by release of $\mathrm{CO}_{2}$ and/or a synthetic odour blend (the BG lure). We compared the attractiveness of this blend to that of the Mbita (MB5) lure, a new synthetic blend of proven efficiency in attracting Afrotropical malaria vectors, and evaluated the additional effect of $\mathrm{CO}_{2}$ to the two odour baits.

Findings: We carried out 6x6 Latin square experiments in two Ae. albopictus-infested areas in Rome, baiting the BG-traps as follows: $\mathrm{CO}_{2}, \mathrm{BG}$ lure, $\mathrm{MB} 5$ lure, $\mathrm{BG}$ lure $+\mathrm{CO}_{2}, \mathrm{MB} 5$ lure $+\mathrm{CO}_{2}$, no bait. $\mathrm{CO}_{2}$ was derived from yeastfermented sugar. Overall, 949 females and 816 males were collected. Baited traps collected significantly more females than unbaited ones. Traps baited with either lures in combination with $\mathrm{CO}_{2}$ were more effective than those baited with $\mathrm{CO}_{2}$ alone. No significant differences were observed in female captures between traps baited with any of the two lures, nor between the two lures, independently from the addition of $\mathrm{CO}_{2}$. The use of $\mathrm{BG}$ lure $+\mathrm{CO}_{2}$ significantly increased males catches compared to unbaited traps.
\end{abstract}

Conclusions: The results suggest a broad significance of the MB5 lure for sampling medically important mosquito species and highlight the high efficacy of the combination of lures $+\mathrm{CO}_{2}$ for female Ae. albopictus and of $\mathrm{BG}$ lure $+\mathrm{CO}_{2}$ for males, leading to consider $\mathrm{CO}_{2}$ as an essential additional cue for the sampling of this species.

Keywords: Aedes albopictus, Mosquito, Adult collections, BG-sentinel trap, Attraction, Odour bait, $\mathrm{CO}_{2}$, Synergism

\section{Findings}

Aedes albopictus is an aggressive daytime-biting mosquito responsible for prominent Chikungunya virus epidemics in the Indian Ocean [1]. Moreover during the past 20 years, the species became a major nuisance in Italy as well as in other southern European countries, where it has also been responsible for endemic Chikungunya transmission in Italy as well as dengue in mainland France and Croatia [2].

\footnotetext{
* Correspondence: marco.pombi@uniroma1.it

1 Dipartimento di Sanità Pubblica e Malattie Infettive, Università di Roma "Sapienza", Rome, Italy

Full list of author information is available at the end of the article
}

While ovitraps are considered the best approach to detect the presence of new establishments of Ae. albopictus, current methods to collect adult specimens in order to better monitor their density and their possible infections with mosquito-borne pathogens, and to establish baseline data for control interventions and assess their efficacy, are not optimal [3]. Presently, the most widely used trap to collect host-seeking Ae. albopictus females is the BG-Sentinel trap (hereafter BG-trap; Biogents A.G., Regensburg, Germany). This device consists of a cylindrical counterflow trap generally baited with a slowrelease pack of a synthetic attractant (BG lure). The fan blows downward into the cylinder so that the attractant is

\section{Ciomed Central}

(c) 2014 Pombi et al.; licensee BioMed Central. This is an Open Access article distributed under the terms of the Creative Commons Attribution License (http://creativecommons.org/licenses/by/4.0), which permits unrestricted use, distribution, and reproduction in any medium, provided the original work is properly credited. The Creative Commons Public Domain Dedication waiver (http://creativecommons.org/publicdomain/zero/1.0/) applies to the data made available in this article, unless otherwise stated. 
blown upward, by overpressure, and out through the upper netting cover. Mosquitoes attracted to the source of odour are drawn into a mesh collecting bag by the downward airflow originating from the fan. Although the BGtrap was originally developed to collect the main dengue vector species Ae. aegypti in tropical areas [4-6], field studies have shown its efficacy in collecting other mosquito species as well, particularly when simultaneously releasing both BG lure and $\mathrm{CO}_{2}$, in North America [7] as well as in Europe [8,9].

A recent study showed a very high attractiveness of selected synthetic blends simulating human odours to host-seeking Afrotropical malaria vectors as well as the filariasis vector Culex quinquefasciatus and other potential mosquito species [10]. Here we report results of field experiments carried out in Rome, Italy, to test the efficacy of one of these blends as a possible alternative to the commonly used BG lure to collect adult Ae. albopictus and to assess the possible effect of $\mathrm{CO}_{2}$ addition to the lures.

\section{Material and methods}

Two $6 \times 6$ Latin square experiments were carried out from 5 to 13 October 2011 in two highly Ae. albopictus-infested areas in Rome $\left(\sim 3000 \mathrm{~m}^{2}\right.$ each and $\sim 1 \mathrm{~km}$ distant one from the other), i.e. the garden of the Unit of Comparative Anatomy of the Department of Biology and Biotechnology of Sapienza University [11] and Verano Cemetery [12]. At each location, six BG-Sentinel traps (Biogents GmbH, Regensburg, Germany) were located at approximately $20 \mathrm{~m}$ from each other and baited with five different odour blends, as follows: $1-\mathrm{CO}_{2}$ (produced by $17.5 \mathrm{~g}$ of fermenting baker's yeast in a sucrose solution $0.29 \mathrm{M}$, as described by Smallegange et al. [13]). 2- BG lure, i.e. standard BG lure sachets, Biogents, consisting of $\mathrm{NH}_{3}$, L-Lactic acid and hexanoic acid in unknown concentrations. 3- Mbita blend, i.e. $\mathrm{MB} 5$ lure, $\mathrm{NH}_{3}$ (25\% in water), $\mathrm{L}-(+)$-Lactic acid (88-92\% in water), tetradecanoic acid (16\% in $\mathrm{EtOH}), 3-$ methyl-1-butanol $(0.01 \%$ in paraffin oil) and butan-1amine $(0.001 \%$ in paraffin oil) [14]. One $\mathrm{mL}$ of each of the solutions was separately embedded in nylon strips $(26.5 \times$ $1.0 \mathrm{~cm}$ ) mounted on a wire frame and placed at the entrance of BG trap [15]. 4- BG lure + $\mathrm{CO}_{2}$. 5- MB5 lure + $\mathrm{CO}_{2}$. 6- a trap activated without any odour and used as a negative control (no bait). Temperature and relative humidity data of the sampling period in the Municipality of Rome were downloaded by the website Archivio Meteo Italia (http://archivio-meteo.distile.it); no rain occurred during the period of the experiment. Every 24 h, all BGtraps were rotated clockwise to the next position for a total of six days. Mosquitoes during each $24 \mathrm{~h}$-sampling were removed from the trap-bags and frozen. Morphological identifications were carried out following Severini et al. [16].
For both Ae. albopictus males and females collected, data were analysed by Generalized Linear Model (GLM) with Poisson distribution with log-link function, dispersion parameter estimated using sampling area, days of collection, trap positions and bait as factors. The final model, including significant factors, was used to calculate the estimated mean trap catches and standard errors followed by a pairwise comparison with LSD correction. All analyses have been performed with SPSS statistical software [17].

\section{Results and discussion}

A total of 1,858 mosquitoes were collected (1,191 in the Anatomy garden and 667 in the Verano cemetery): $95 \%$ of these were Ae. albopictus and 5\% Culex pipiens. Table 1 shows the median and total catches of Ae. albopictus females and males for each site and for each tested odour blend. Overall, a comparable number of females were collected in the two areas, while a significantly higher number of males were collected in the Anatomy garden (i.e. males:females ratio was 1.5 in the Anatomy garden and 0.3 in Verano; $\left.\chi^{2}=229.1 ; \mathrm{p}<0.0001\right)$. Since there is no reason to assume that this reflects a real difference in sexratio in the two areas, the observed difference may be due to their distinctive ecological features. In particular, it may be hypothesized that the lower abundance of visual landmarks for male swarming [18] in Anatomy garden (as opposed to Verano cemetery where landmarks such as graves or trees are very abundant) makes the white/dark contrast of BG-Sentinel trap the major swarming landmark in this area $[19,20]$.

While the ambient temperature remained roughly stable during the experiments, fluctuations in daily female collections were positively correlated with relative humidity variations (Pearson's $R^{2}=0.41, p=0.026$; Figure 1 ). This phenomenon, already observed in a previous study [21], could be due to a stimulation of host-seeking behaviour by increasing relative humidity, which may be perceived by female mosquitoes as an indication of possible imminent rains and, thus, of increasing availability of oviposition/breeding sites [22]. This hypothesis is also supported by the lack of correlation between daily male collections and relative humidity.

The GLM model for Ae. albopictus females retained sampling area $\left(\chi^{2}=22.0 ; \mathrm{p}=0.001\right)$, date of collection $\left(\chi^{2}=38.3 ; \mathrm{p}<0.0001\right)$ and odour bait tested $\left(\chi^{2}=4.39 ; \mathrm{p}<\right.$ $0.036)$ as significant effects. BG-trap position was shown not to affect the model significantly, although exposure to sun has been shown to reduce collection efficiency [21]. Significant differences were observed in the mean number of females collected daily in the two sites with traps baited with the different blends (Figure 2A; Table 2): i) all baited traps were significantly more effective than the unbaited ones ( $t$-probabilities of pairwise differences; $\mathrm{P}<0.05$ ); ii) 
Table 1 Descriptive statistics of Aedes albopictus collected with different odour blends

\begin{tabular}{|c|c|c|c|c|c|c|c|}
\hline \multirow[t]{2}{*}{ Bait } & \multirow[t]{2}{*}{ Sex } & \multicolumn{3}{|c|}{ Anatomy garden } & \multicolumn{3}{|c|}{ Verano cemetery } \\
\hline & & Median & 5-95\% Percentiles & N (\%) & Median & 5-95\% Percentiles & N (\%) \\
\hline \multirow[t]{2}{*}{ No bait } & females & 5 & $0-10$ & $30(29 \%)$ & 7 & $1-18$ & 49 (77\%) \\
\hline & males & 7 & $0-44$ & 72 (71\%) & 1 & $0-8$ & $15(23 \%)$ \\
\hline \multirow[t]{2}{*}{$\mathrm{CO}_{2}$} & females & 10 & $0-20$ & $64(47 \%)$ & 8 & $1-28$ & 59 (84\%) \\
\hline & males & 13 & $5-18$ & 71 (53\%) & 1 & $0-6$ & $11(16 \%)$ \\
\hline \multirow[t]{2}{*}{ MB5 lure } & females & 7 & $5-11$ & $44(40 \%)$ & 12 & $2-37$ & 99 (79\%) \\
\hline & males & 12 & $1-20$ & $67(60 \%)$ & 4 & $0-9$ & $26(21 \%)$ \\
\hline \multirow[t]{2}{*}{$\mathrm{MB5}$ lure $+\mathrm{CO}_{2}$} & females & 15 & $11-28$ & $97(44 \%)$ & 19 & $7-23$ & $96(74 \%)$ \\
\hline & males & 16 & $6-48$ & $121(56 \%)$ & 6 & $0-14$ & $34(26 \%)$ \\
\hline \multirow[t]{2}{*}{ BG lure } & females & 14 & $10-24$ & $93(44 \%)$ & 10 & $0-40$ & 87 (80\%) \\
\hline & males & 21 & $4-34$ & $118(56 \%)$ & 2 & $0-10$ & $22(20 \%)$ \\
\hline \multirow[t]{2}{*}{$\mathrm{BG}$ lure $+\mathrm{CO}_{2}$} & females & 18 & $10-32$ & $118(35 \%)$ & 18 & $2-36$ & $113(74 \%)$ \\
\hline & males & 37 & $5-95$ & $219(65 \%)$ & 7 & $0-19$ & $40(26 \%)$ \\
\hline Total females & & & & $446(40 \%)$ & & & $503(77 \%)$ \\
\hline Total males & & & & $668(60 \%)$ & & & $148(23 \%)$ \\
\hline
\end{tabular}

Median and 5-95\% percentile intervals of Ae. albopictus females and males collected with BG-Sentinel traps baited with different odour blends (BG lure and MB5 lure with/without $\mathrm{CO}_{2}$ ) in two areas in Rome (Italy). No bait = negative control.

traps baited with either lures in combination with $\mathrm{CO}_{2}$ were more effective than those baited with $\mathrm{CO}_{2}$ alone (MB5 lure $+\mathrm{CO}_{2}$ vs $\mathrm{CO}_{2}: \mathrm{P}=0.052 ; \mathrm{BG}$ lure $+\mathrm{CO}_{2}$ vs $\left.\mathrm{CO}_{2}: \mathrm{P}=0.005\right)$. No significant differences were observed between traps baited with MB5 lure alone versus MB5 lure $+\mathrm{CO}_{2}$ and with BG lure alone versus $\mathrm{BG}$ lure $+\mathrm{CO}_{2}$. Finally, no significant differences were observed between the two lures neither in the absence, nor in the presence of $\mathrm{CO}_{2}$, although the highest collections were obtained with combinations of each lure with $\mathrm{CO}_{2}$.

GLM model of male collections - of which significant variables are: date of collection $\left(\chi^{2}=68.5 ; \mathrm{p}<0.0001\right)$, bait tested $\left(\chi^{2}=35.7 ; \mathrm{p}<0.0001\right)$ and trap position $\left(\chi^{2}=\right.$
27.7; p-0.002) - showed a trend only partially consistent with the one observed for females (Figure 2B, Table 2): i) baited traps were not significantly more effective than the not baited ones (probably due to low average catch sizes and large variations in estimates) except for BG lure $+\mathrm{CO}_{2}$ ( $\mathrm{t}$-probabilities of pairwise differences; $\mathrm{P}=$ $0.005)$, ii) traps baited with $\mathrm{BG}$ lure, with or without $\mathrm{CO}_{2}$, were more effective than those baited with $\mathrm{CO}_{2}$ alone (BG lure vs $\mathrm{CO}_{2}: \mathrm{P}=0.035$; $\mathrm{BG}$ lure $+\mathrm{CO}_{2}$ vs $\mathrm{CO}_{2}$ : 0.002), whereas MB5 lure was more effective than $\mathrm{CO}_{2}$ alone only in combination with $\mathrm{CO}_{2}(\mathrm{P}=0.019)$ iii) $\mathrm{BG}$ lure showed increased performance when $\mathrm{CO}_{2}$ was added to the blend ( $\mathrm{BG}$ lure $+\mathrm{CO}_{2}$ vs $\mathrm{BG}$ lure: $\mathrm{P}=$

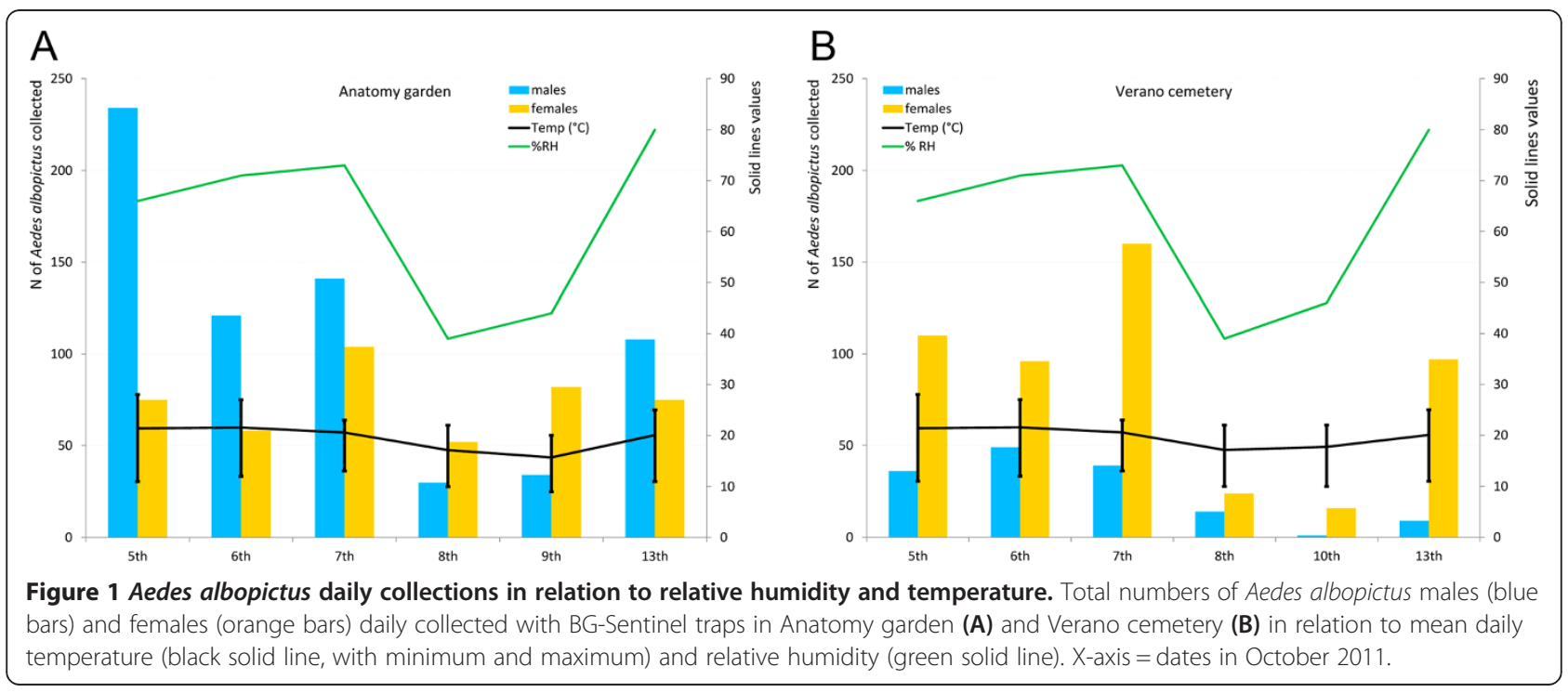




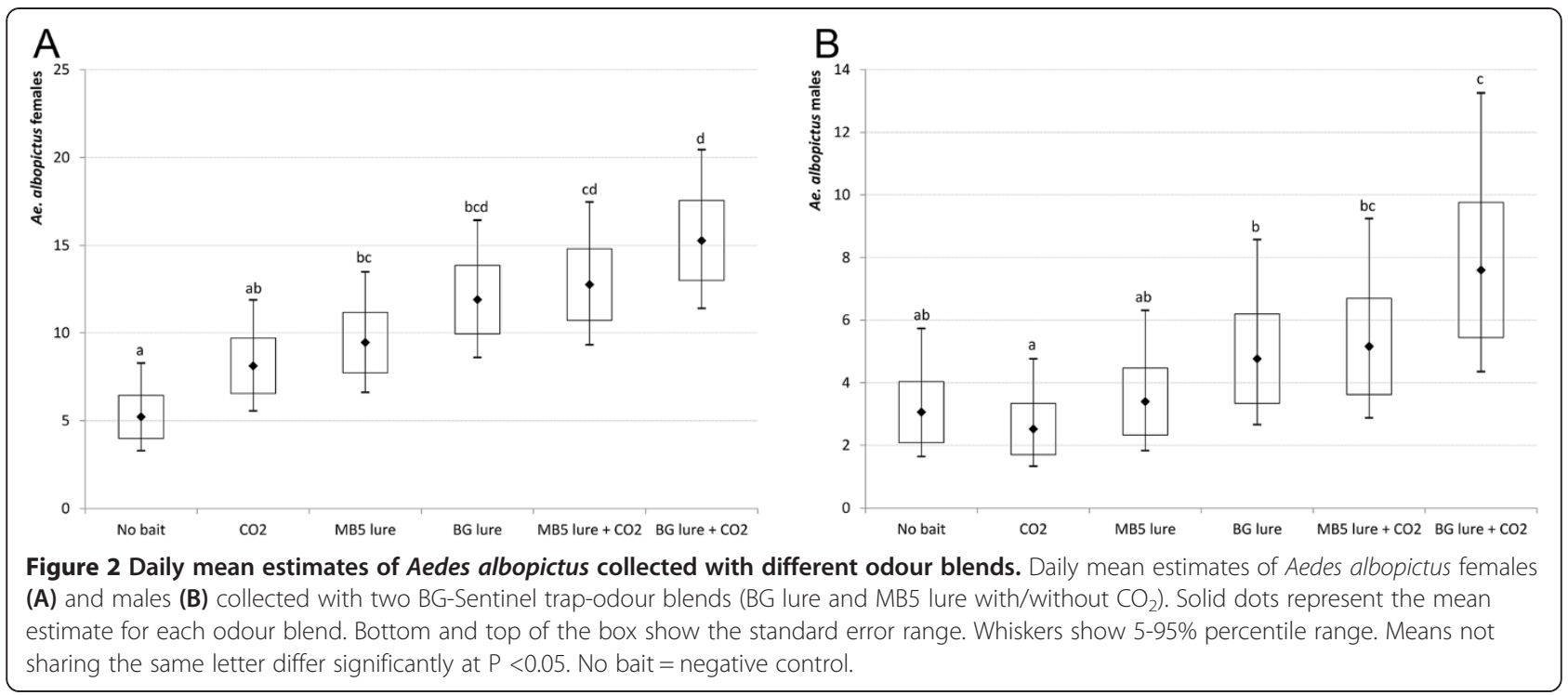

0.038), whereas no significant differences were observed between traps baited with MB5 lure alone versus MB5 lure $+\mathrm{CO}_{2}$. The attractive effect of odour blends is likely due to the fact that Ae. albopictus males, although not blood-feeding, often mate with females in proximity of potential hosts and thus seek for hosts to increase their reproductive success [18].

In conclusion, the study demonstrates that the MB5 lure - which was developed to specifically attract highly anthropophilic Afrotropical malaria vectors and was shown to be very efficacious in this respect [15] - is as attractive as the BG lure to Ae. albopictus despite the

\section{Table 2 Pairwise comparisons of predicted mean estimates of Aedes albopictus collected with different odour blends}

\begin{tabular}{llllll}
\hline Females & & & & & \\
& No bait & $\mathrm{CO}_{2}$ & $\mathrm{MB} 5$ lure & $\mathrm{BG}$ lure & $\mathrm{MB} 5$ lure $+\mathrm{CO}_{2}$ \\
$\mathrm{CO}_{2}$ & $\mathrm{~ns}$ & & & & \\
$\mathrm{MB} 5$ lure & 0.034 & $\mathrm{~ns}$ & & & \\
$\mathrm{BG}$ lure & 0.02 & $\mathrm{~ns}$ & $\mathrm{~ns}$ & & \\
$\mathrm{MB} 5$ lure $+\mathrm{CO}_{2}$ & 0.001 & 0.052 & $\mathrm{~ns}$ & $\mathrm{~ns}$ & \\
$\mathrm{BG}$ lure $+\mathrm{CO}_{2}$ & 0.000 & 0.005 & 0.025 & $\mathrm{~ns}$ & $\mathrm{~ns}$ \\
Males & & & & & \\
& $\mathrm{No}$ bait & $\mathrm{CO}_{2}$ & $\mathrm{MB} 5$ lure & $\mathrm{BG}$ lure & $\mathrm{MB} 5$ lure $+\mathrm{CO}_{2}$ \\
$\mathrm{CO}{ }_{2}$ & $\mathrm{~ns}$ & & & & \\
MB5 lure & $\mathrm{ns}$ & $\mathrm{ns}$ & & & \\
$\mathrm{BG}$ lure & $\mathrm{ns}$ & 0.035 & $\mathrm{~ns}$ & & \\
$\mathrm{MB} 5$ lure $+\mathrm{CO}_{2}$ & $\mathrm{~ns}$ & 0.019 & $\mathrm{~ns}$ & $\mathrm{~ns}$ & \\
$\mathrm{BG}$ lure $+\mathrm{CO}_{2}$ & 0.005 & 0.002 & 0.007 & 0.038 & $\mathrm{~ns}$
\end{tabular}

P-values of pairwise comparisons of predicted mean estimates of $A e$. albopictus females and males collected with different odour blends (BG lure and MB5 lure with/without $\mathrm{CO}_{2}$ ) as obtained by GLM. Only $95 \%$ significant $p$-values are shown. $n s=$ non-significant $p$-value. No bait $=$ negative control. generalist feeding habits of this species [12]. This could imply that the MB5 lure can be effectively applied in sampling schemes were both anthropophilic and generalist species are targeted, although its attractiveness to tropical mosquito species remains to be compared to that of the BG lure. The availability of synthetic mosquito lures that are as attractive as a human is highly advantageous as odour-baited traps can be placed across a wide area without the need for operational visits for surveillance purposes. Moreover, recent studies have demonstrated that the residual effect of the MB5 lure exceeds 40 days opening the possibility to leave traps running unattended for several weeks, with a continuous release of attractants [10].

The results show that the addition of the synthetic lures to $\mathrm{CO}_{2}$ increases trap performance, thus confirming the importance of this blend combination in mosquito attraction already shown from previous studies with live animals [23]. Addition of $\mathrm{CO}_{2}$ to $\mathrm{BG}$ lure and MB5 was shown to be highly attractive also to $A e$. aegypti in the Brazilian Amazon region [24] and in Iquitos, Peru (W. Takken et al., unpublished data), respectively, further supporting addition of $\mathrm{CO}_{2}$ as an essential element of synthetic odour baits for mosquitoes. Overall, odour-baited traps, as used in the current study, can be used in epidemiological studies of vector-borne disease risk estimates as well as for establishing the level of mosquito nuisance.

Moreover, the method used to release of $\mathrm{CO}_{2}$ by yeast fermentation of sugar was shown to be effective also for Ae. albopictus in temperate climates. This method, already representing a cheap and reliable method for collection of other tropical mosquito species, has the clear operational advantage to obviate the more expensive and demanding use of gas tanks or dry ice $[13,25]$. 
Finally, the high numbers of males collected in this study show that BG-Sentinel traps baited with either odours in combination with $\mathrm{CO}_{2}$ represent an effective tool for measurements of male dispersal, mating behaviour and longevity, which are presently constrained by the lack of efficient sampling tools.

\section{Conclusions}

The results confirm the efficacy of BG-Sentinel trap baited with the standard BG lure and synergized with $\mathrm{CO}_{2}$ in collecting not only Ae. albopictus females, but also males, whose sampling is increasingly important in the frame of studies aimed to evaluate the potential of sterile insect technique control approaches [26]. Moreover, the results indicate that the MB5 lure, which was developed to attract anthropophilic Afrotropical malaria vectors, is also effective to attract mosquito species, such Ae. albopictus, with generalist trophic habits and thus involved in the transmission of human, as well as zoonotic pathogens.

\section{Abbreviations}

MB5: Mbita blend; BG-trap: Biogents BG-Sentinel trap.

\section{Competing interests}

The authors declare that they have no competing interests.

\section{Authors' contributions}

Designed the study: MP, AdT, WT. Performed the data collection: MP, BC, FJ. Analyzed the data: MP, NOV. Wrote the paper: MP, AdT, WT. All authors read and approved the final version of the manuscript.

\section{Acknowledgements}

We are grateful to the personnel of AMA-Cimiteri Capitolini and of the Unit of Comparative Anatomy of the Department of Biology and Biotechnology of Sapienza University for hosting our experiments and for helping with the logistics. This work has been funded by Italian Ministry of Defense -Ispettorato Generale della Sanità Militare (TelesorveglianzaVettoriale project) and by EU grant FP7-261504 EDENext, and is catalogued by the EDENext Steering Committee as EDENext N. 252 (http://www.edenext.eu). The contents of this publication are the sole responsibility of the authors and do not necessarily reflect the views of the Ministry nor of European Commission.

\section{Author details}

${ }^{1}$ Dipartimento di Sanità Pubblica e Malattie Infettive, Università di Roma "Sapienza", Rome, Italy. 'Laboratory of Entomology, Wageningen University and Research Centre, Wageningen, The Netherlands.

Received: 8 August 2014 Accepted: 28 November 2014 Published online: 11 December 2014

\section{References}

1. Pialoux G, Gaüzère B-A, Jauréguiberry S, Strobel M: Chikungunya, an epidemic arbovirosis. Lancet Infect Dis 2007, 7:319-327.

2. Medlock JM, Hansford KM, Schaffner F, Versteirt V, Hendrickx G, Zeller H, Van Bortel W: A review of the invasive mosquitoes in Europe: ecology, public health risks, and control options. Vector Borne Zoonotic Dis 2012, 12:435-447.

3. Marrama Rakotoarivony L, Schaffner F: ECDC Guidelines for the Surveillance of Invasive Mosquitoes in Europe, Volume 17. Stockholm: European Centre for Disease Prevention and C ontrol; 2012:95.

4. Krockel U, Rose A, Eiras AE, Geier M: New tools for surveillance of adult yellow fever mosquitoes: comparison of trap catches with human landing rates in an urban environment. J Am Mosa Control Assoc 2006, 22:229-238.

5. Maciel-de-Freitas R, Eiras AE, Lourenço-de-Oliveira R: Field evaluation of effectiveness of the BG-Sentinel, a new trap for capturing adult Aedes aegypti (Diptera: Culicidae). Mem Inst Oswaldo Cruz 2006, 101:321-325.
6. Meeraus W, Armistead J, Arias J: Field comparison of novel and gold standard traps for collecting Aedes albopictus in northern Virginia. J Am Mosa Control Assoc 2008, 24:244-248.

7. Farajollahi A, Kesavaraju B, Price DC, Williams GM, Healy SP, Gaugler R, Nelder MP: Field efficacy of BG-Sentinel and industry-standard traps for Aedes albopictus (Diptera: Culicidae) and West Nile virus surveillance. J Med Entomol 2009, 46:919-925.

8. Drago A, Marini F, Caputo B, Coluzzi M, Della Torre A, Pombi M: Looking for the gold standard: assessment of the effectiveness of four traps for monitoring mosquitoes in Italy. J Vector Ecol 2012, 37:117-123.

9. Lühken R, Pfitzner WP, Börstler J, Garms R, Huber K, Schork N, Steinke S, Kiel $E$, Becker N, Tannich E, Krüger A: Field evaluation of four widely used mosquito traps in Central Europe. Parasit Vectors 2014, 7:268.

10. Mukabana WR, Mweresa CK, Otieno B, Omusula P, Smallegange RC, van Loon JJ, Takken W: A novel synthetic odorant blend for trapping of malaria and other African mosquito species. J Chem Ecol 2012, 38:235-244.

11. Caputo B, lenco A, Cianci D, Pombi M, Petrarca V, Baseggio A, Devine GJ, Della Torre A: The "Auto-Dissemination" approach: a novel concept to fight Aedes albopictus in urban areas. PLoS Negl Trop Dis 2012, 6:e1793.

12. Valerio L, Marini F, Bongiorno G, Facchinelli L, Pombi M, Caputo B, Maroli M, Della Torre A: Host-feeding patterns of Aedes albopictus (Diptera: Culicidae) in urban and rural contexts within Rome province, Italy. Vector Borne Zoonotic Dis 2010, 10:291-294.

13. Smallegange RC, Schmied WH, van Roey KJ, Verhulst NO, Spitzen J, Mukabana WR, Takken W: Sugar-fermenting yeast as an organic source of carbon dioxide to attract the malaria mosquito Anopheles gambiae. Malar J 2010, 9:292.

14. Menger DJ, VAN Loon JJA, Takken W: Assessing the efficacy of candidate mosquito repellents against the background of an attractive source that mimics a human host. Med Vet Entomol 2014, 28:407-413.

15. Hiscox A, Otieno B, Kibet A, Mweresa CK, Omusula P, Geier M, Rose A, Mukabana WR, Takken W: Development and optimization of the Suna trap as a tool for mosquito monitoring and control. Malar J 2014, 13:257.

16. Severini F, Toma L, Di Lucia M, Romi R: Le Zanzare Italiane: Generalità e Identificazione degli Adulti (Diptera, Culicidae). Fragm Entomol 2009, 41:213-372.

17. IBM Corp: IBM SPSS Statistics for Windows. 2011.

18. Hawley WA: The biology of Aedes albopictus. J Am Mosq Control Assoc Supp/ 1988, 1:1-39.

19. Gubler DJ, Bhattacharia NC: Swarming and mating of Aedes (S.) albopictus in nature. Mosq News 1972, 32:219-223.

20. Tuten HC, Stone CM, Dobson SL: Swarming behavior of Aedes polynesiensis (Diptera: Culicidae) and characterization of swarm markers in American Samoa. J Med Entomol 2013, 50:740-747.

21. Crepeau TN, Healy SP, Bartlett-Healy K, Unlu I, Farajollahi A, Fonseca DM: Effects of biogents sentinel trap field placement on capture rates of adult Asian tiger mosquitoes. Aedes Albopictus PLoS One 2013, 8:e60524.

22. Clements AN: The Biology of Mosquitoes: Sensory, Reception, and Behaviour. First editionth edition. New York: CABl; $1999: 752$.

23. Vickery C, Meadows K, Baughman I: Synergism of carbon dioxide and chick as bait for Culex nigripalpus. Mosq News 1966, 26:507-509.

24. Degener CM, Eiras AE, Azara TMF, Roque RA, Rösner S, Codeço CT, Nobre AA, Rocha ESO, Kroon EG, Ohly JJ, Geier M: Evaluation of the effectiveness of mass trapping with BG-sentinel traps for dengue vector control: a cluster randomized controlled trial in Manaus, Brazil. J Med Entomol 2014, 51:408-420.

25. Mweresa CK, Omusula P, Otieno B, van Loon JJA, Takken W, Mukabana WR: Molasses as a source of carbon dioxide for attracting the malaria mosquitoes Anopheles gambiae and Anopheles funestus. Malar J 2014, 13:160.

26. Lacroix R, Delatte H, Hue T, Dehecq JS, Reiter P: Adaptation of the BG-Sentinel trap to capture male and female Aedes albopictus mosquitoes. Med Vet Entomol 2009, 23:160-162.

\section{doi:10.1186/s13071-014-0580-9}

Cite this article as: Pombi et al:: Field evaluation of a novel synthetic odour blend and of the synergistic role of carbon dioxide for sampling host-seeking Aedes albopictus adults in Rome, Italy. Parasites \& Vectors 2014 7:580 